\title{
Marketing research in China during the 40-year reform and opening
}

\author{
$\mathrm{Yu} \mathrm{Hu}{ }^{1^{*}}$ and Yonggui Wang ${ }^{2}$
}

\author{
* Correspondence: 201700320062@ \\ uibe.edu.cn \\ ${ }^{1}$ University of International Business \\ and Economics, No.10, Huixin \\ Dongjie, Chaoyang District, Beijing \\ 100029, China \\ Full list of author information is \\ available at the end of the article
}

\begin{abstract}
China's reform and opening up policy initiated by the then leader Deng Xiaoping have undergone a 40-year process since 1978. This period was marked by one of the greatest economic reforms in modern history. In this study, we extract literature focused on the Chinese marketization context and marketing practices published in top-tier international marketing journals and Chinese management journals between 1978 and 2018. This study identifies the research questions and research domains investigated in our selected literature. The authors hope to reveal the general landscape and evolution made in the context of this unique period in Chinese history. This thematically focused literature review provides marketing scholars with a snapshot of the academic marketing research in China and gives rise to novel research directions related to the deepening of the economic reform.
\end{abstract}

Keywords: China, Reform and opening up, Marketing research and practice, Chinese consumer, Marketing strategy

\section{Introduction}

The marketing environment in China has been rapidly changing since 1978. Before 1978, China was practicing a highly concentrated planned economy. Firms organized their production activities according to strict national administrative policies. Products were allocated by national departments which managed resources and trade. Within this planned economy, firms did not have access to the market and their marketing activities simply followed a pre-arranged administrative process. When the reform and opening up policy was implemented, many different aspects of Chinese socioeconomic life were vastly transformed, for both consumers and business participants.

This transformation occurred in different stages, starting from the agricultural sector and reaching almost every industry and a large number of marketing entities. According to national statistics, by the end of 2018, there were around 34 million enterprise units registered in China, which involved over 110 million participating marketing entities. ${ }^{1}$ The process of marketization provided marketing researchers with a growing number of business entities and practical phenomena to investigate. In addition, the large population of Chinese consumers and their eastern cultural background made a unique phenomenon and novel data in consumer behavior studies. Moreover, the marketing environment was constantly reshaped by the ongoing changes in regulations

\footnotetext{
${ }^{1}$ The statistical data refers to the State Administration for Market Regulation of China.
}

(c) The Author(s). 2020 Open Access This article is distributed under the terms of the Creative Commons Attribution 4.0 International License (http://creativecommons.org/licenses/by/4.0/), which permits unrestricted use, distribution, and reproduction in any medium, provided you give appropriate credit to the original author(s) and the source, provide a link to the Creative Commons license, and indicate if changes were made. 
and policies guided by the evolution towards a market-oriented economy. These changes also served as natural experiments into business evolution in an emerging market for marketing researchers. At the beginning of the reform, the Chinese market was not accessible to foreign products but a growing income and the accumulation of wealth increased the purchasing power of Chinese customers, which made China a mostly unexplored marketplace for foreign companies.

Currently, the national reform and opening up of the market are gaining new grounds. The present goal is to overcome existing challenges to push the Chinese socioeconomic condition to a higher level. To do so, researchers need to look back on marketing studies during the 40 years of the reform and opening up. We reviewed both international and Chinese marketing journals to offer an insightful review of these past studies. The remainder of this article is organized as follows. First, we introduce the method used to collect the sample papers, which outlines how we have selected papers dealing with marketing research in China and processed them in this study. Then, the findings are exposed within different categories according to research themes. In the final two sections, we discuss possible research directions and conclude this study.

\section{Review method}

\section{Samples (international journals)}

To collect sample papers, we chose four top-tier international marketing journals from the UTD 24 list. $^{2}$ These included Journal of Marketing, Journal of Marketing Research, Journal of Consumer Research and Marketing Science. We collected both theoretical and practical research papers published from 1978 to 2018 which focused on China. We shortlisted papers, through each journal's official website, which featured the words "China" or "Chinese" in title, abstract or keywords. Papers which featured the words "China" or "Chinese" in the full text were judged individually for relevancy. We excluded duplicates and papers which were not research papers. The final list is shown in Table 1.

\section{Samples (Chinese journals)}

The targeted Chinese journals were Management World, Nankai Business Review and Journal of Marketing Science, three leading management journals in China. To collect sample papers, we searched for the term "marketing" in title, abstract or keywords. We also searched for marketing-related terms (e.g., brand, consumer and customer). After exclusion of papers that did not report marketing research, we obtained 798 papers: 272 from Management World, 339 from Nankai Business Review, and 178 from Journal of Marketing Science.

\section{Review methods}

We employed both qualitative and quantitative methods in our review. For international journals, we utilized qualitative review methods to identify the relevance of sample papers to our research agenda. Research questions were divided between theoretical and practical concerns. We defined theoretical papers as those whose authors aimed to fill research gaps that had not been addressed in prior literature. On the contrary, practical papers tend to focus on interpreting specific phenomena and offering

\footnotetext{
${ }^{2}$ The information about "UTD 24" is available at http://jindal.utdallas.edu/the-utd-top-100-business-schoolresearch-rankings/index.php, 4th August, 2018.
} 
Table 1 Numbers of paper selected from international journals

\begin{tabular}{|c|c|c|c|c|c|}
\hline & \multicolumn{4}{|c|}{ Location of the search keyword } & \multirow{2}{*}{$\begin{array}{l}\text { Fine } \\
\text { tuned }\end{array}$} \\
\hline & Title & Keyword & Abstract & Full text & \\
\hline \multicolumn{6}{|l|}{ Journal of Marketing } \\
\hline Search key word: China & 4 & 3 & 11 & 107 & \multirow[t]{3}{*}{25} \\
\hline Search key word: Chinese & 0 & 0 & 6 & 71 & \\
\hline Duplication exclued in total & & & & 94 & \\
\hline \multicolumn{6}{|l|}{ Journal of Marketing Research } \\
\hline Search key word: China & 0 & 1 & 8 & 73 & \multirow[t]{3}{*}{13} \\
\hline Search key word: Chinese & 2 & 1 & 12 & 61 & \\
\hline Duplication exclued in total & & & & 134 & \\
\hline \multicolumn{6}{|l|}{ Journal of Consumer Research } \\
\hline Search key word: China & 2 & 0 & 5 & 155 & \multirow[t]{3}{*}{12} \\
\hline Search key word: Chinese & 5 & 0 & 5 & 168 & \\
\hline Duplication excluded in total & & & & 225 & \\
\hline \multicolumn{6}{|l|}{ Marketing Science } \\
\hline Search key word: China & 0 & 0 & 3 & 104 & \multirow[t]{3}{*}{6} \\
\hline Search key word: Chinese & 1 & 0 & 2 & 40 & \\
\hline Duplication excluded in total & & & & 130 & \\
\hline
\end{tabular}

Notes. The results are subject to the time between January 1978 and October 2018

methods to overcome managerial problems. We assessed the relevance of the papers for marketing research in China through the lens of their research contexts, the origin of their constructs and whether the study was comparative or aiming to solve or provide insights on unique managerial problems in China. Thus, only studies focusing on the Chinese context were deemed relevant. Table 2 summarizes the methods used to determine the relevancy of each paper in this review.

For Chinese research papers, we first provided general statistics on the publication status of each journal. Then, we identified main research fields and statistically depicted the changing patterns of each field over time.

\section{Findings}

\section{Review findings in international journals}

The research domains of our sample papers were divided into four different categories: marketing environment, marketing strategy, consumer behavior and international marketing. Table 3 lists the top 5 most-cited papers from our selected sample.

We reviewed each sample paper by examining its research question, data collection, research design, thematic focus, theoretical purpose and citation status; this helped identify three significant characteristics of the existing literature. First, the cultural element has been consistently studied in marketing research over time, both from the customer and market perspectives. Constructs regarding Chinese culture were mostly observed in relation to mediators and moderators. However, in recent decades, the percentage of culture-related papers has gradually decreased owing to the emergence of state-of-the-art marketing technologies. Second, the institutional environment has been studied frequently as a contextual factor because of its unique role within the Chinese 
Table 2 The method for determination of relevancy

\begin{tabular}{|c|c|c|c|c|c|c|}
\hline \multirow{2}{*}{$\begin{array}{l}\text { Level of } \\
\text { relevancy }\end{array}$} & \multicolumn{5}{|c|}{ Identifiers } & \multirow[t]{2}{*}{ Example } \\
\hline & $\begin{array}{l}\text { China } \\
\text { oriented } \\
\text { data }\end{array}$ & $\begin{array}{l}\text { Comparative } \\
\text { study }\end{array}$ & $\begin{array}{l}\text { Unique } \\
\text { Chinese } \\
\text { context }\end{array}$ & $\begin{array}{l}\text { China } \\
\text { oriented } \\
\text { constructs }\end{array}$ & $\begin{array}{l}\text { China } \\
\text { oriented } \\
\text { discussion }\end{array}$ & \\
\hline 1 & $\sqrt{ }$ & $\sqrt{ }$ & & & & $\begin{array}{l}\text { Calantone et al. (1996); Song et al. } \\
\text { (2000); Grewal and Dharwadkar (2002); } \\
\text { Chan et al. (2010); Samaha et al. (2014) }\end{array}$ \\
\hline 2 & $\sqrt{ }$ & $\sqrt{ }$ & $\sqrt{ }$ & & & $\begin{array}{l}\text { Schmitt et al. (1994); Luo et al. (2006); } \\
\text { Dong and Tian (2009); Keh and Pang } \\
\text { (2010); Hermosilla et al. (2018) }\end{array}$ \\
\hline 3 & $\sqrt{ }$ & & $\sqrt{ }$ & $\sqrt{ }$ & & $\begin{array}{l}\text { Tavassoli (1999); Zhang and Schmitt } \\
\text { (2001); Fang et al. (2008); Petersen et al. } \\
\text { (2015); Wang et al. (2017a) }\end{array}$ \\
\hline 4 & $\sqrt{ }$ & & $\sqrt{ }$ & $\sqrt{ }$ & $\sqrt{ }$ & $\begin{array}{l}\text { Tse et al. (1989); Zhou et al. (2005); Gu } \\
\text { et al. (2008); Chu and Manchanda } \\
\text { (2016); Wu (2015) }\end{array}$ \\
\hline
\end{tabular}

Notes.The paper surveyed is more relevant to China when the level of relevancy is higher

socioeconomic framework. Third, the increasing attention granted to technological advances in telecommunications, networks and social media has generated new marketing practices and research topics. We summarize the academic endeavors focusing on the cultural element, institutional environment and technological advancement in Table 4.

\section{Marketing environment}

The increase in consumer purchasing power brought about by rapid economic growth has given rise to Chinese consumerism. Zhao and Belk (2008) found evidence of the increasing consumerism in Chinese consumer culture by analyzing the advertising content in China Daily from 1978 to 2003. A longitudinal study on the evolution of Chinese consumerism at a macro level over a 10-year period, since the economic transformation from planned economy to market economy in 1978, examined how policy change served as a natural experiment for researchers to observe the shift in consumers' values (Tse et al. 1989). Much cross-cultural research on consumer behaviors based on language differences between Chinese and English has been conducted. Schmitt et al. (1994) pointed out that structural differences between the present tense of the Chinese and English language affect consumers' mental representations and subsequently influence memory of verbal information. The experiment reveals a relationship between language structure and consumer behavior from a memory coding perspective. In another study, Schmitt and Zhang (1998) further explored the influence of language structure on consumers' categorization process. Specifically, covering different languages from the East-Asian region and English, they investigated how language structure shapes the classifiers which determine customer cognition, judgment and choice. Differences in information processing regarding short-term memory components caused by linguistic characteristics have been studied by Tavassoli (1999). He showed that languages are important cultural elements in shaping consumers' information processing progress. His study used experiments to justify the hypothesis that English words provoke a higher degree of phonological information processing, which helps temporal memory encoding, while Chinese words provoke a higher degree of contextual and visual-semantic information processing, which helps associative memory 
Table 3 Most cited research papers in our selection (Top 5)

\begin{tabular}{|c|c|c|c|c|c|c|}
\hline \multirow[t]{2}{*}{ Title } & \multicolumn{6}{|c|}{ Research elements } \\
\hline & Authors & Year & $\begin{array}{l}\text { Resarch question/ } \\
\text { purpose }\end{array}$ & Main finding & $\begin{array}{l}\text { Journal } \\
\text { name }\end{array}$ & Citation \\
\hline $\begin{array}{l}\text { The effects of } \\
\text { strategic orientations } \\
\text { on technology- and } \\
\text { market-based break- } \\
\text { through innovations }\end{array}$ & $\begin{array}{l}\text { Zhou } \\
\text { et al. }\end{array}$ & 2005 & $\begin{array}{l}\text { What is the strategic } \\
\text { orientation's effect on } \\
\text { different types of } \\
\text { innovation(technological- } \\
\text { based or market-based)? }\end{array}$ & $\begin{array}{l}\text { Different market forces } \\
\text { exert significant } \\
\text { influence on } \\
\text { technology- and } \\
\text { market-based innova- } \\
\text { tions, and these two } \\
\text { types of innovations } \\
\text { affect firm perform- } \\
\text { ance differently. }\end{array}$ & $\begin{array}{l}\text { Journal of } \\
\text { Marketing }\end{array}$ & 558 \\
\hline $\begin{array}{l}\text { Market knowledge } \\
\text { dimensions and cross- } \\
\text { functional collabor- } \\
\text { ation: Examining the } \\
\text { different routes to } \\
\text { product innovation } \\
\text { performance }\end{array}$ & $\begin{array}{l}\text { Luca } \\
\text { et al. }\end{array}$ & 2007 & $\begin{array}{l}\text { What are the dimensions } \\
\text { or characteristics of } \\
\text { market knowledge and } \\
\text { how and why these } \\
\text { resources influence } \\
\text { product innovation } \\
\text { performance? }\end{array}$ & $\begin{array}{l}\text { Market knowledge } \\
\text { specificity and cross- } \\
\text { functional collabor- } \\
\text { ation affect product } \\
\text { innovation perform- } \\
\text { ance through know- } \\
\text { ledge integration } \\
\text { mechanisms.The effect } \\
\text { of market knowledge } \\
\text { depth is partially medi- } \\
\text { ated, market know- } \\
\text { ledge breadth has a } \\
\text { direct, unmediated ef- } \\
\text { fect on product } \\
\text { innovation } \\
\text { performance. }\end{array}$ & $\begin{array}{l}\text { Journal of } \\
\text { Marketing }\end{array}$ & 324 \\
\hline $\begin{array}{l}\text { Radical innovation } \\
\text { across nations: The } \\
\text { preeminence of } \\
\text { corporate culture }\end{array}$ & $\begin{array}{l}\text { Tellis } \\
\text { et al. }\end{array}$ & 2009 & $\begin{array}{l}\text { How coporate culture } \\
\text { affect radical innovation? }\end{array}$ & $\begin{array}{l}\text { Corporate culture is } \\
\text { the strongest driver of } \\
\text { radical innovation } \\
\text { across nations; culture } \\
\text { consists of three } \\
\text { attitudes and three } \\
\text { practices. The } \\
\text { commercialization of } \\
\text { radical innovations } \\
\text { translates into a firm's } \\
\text { financial performance. }\end{array}$ & $\begin{array}{l}\text { Journal of } \\
\text { Marketing }\end{array}$ & 276 \\
\hline $\begin{array}{l}\text { The effects of } \\
\text { business and political } \\
\text { ties on firm } \\
\text { performance: } \\
\text { Evidence from China }\end{array}$ & $\begin{array}{l}\text { Sheng } \\
\text { et al. }\end{array}$ & 2011 & $\begin{array}{l}\text { What are the different } \\
\text { roles business versus } \\
\text { political ties play on firm } \\
\text { performance? }\end{array}$ & $\begin{array}{l}\text { Business ties have a } \\
\text { stronger positive effect } \\
\text { on performance than } \\
\text { political ties, and both } \\
\text { effects depend on } \\
\text { institutional and } \\
\text { market environments. }\end{array}$ & $\begin{array}{l}\text { Journal of } \\
\text { Marketing }\end{array}$ & 251 \\
\hline $\begin{array}{l}\text { Impact of emerging } \\
\text { markets on marketing: } \\
\text { Rethinking existing } \\
\text { perspectives and } \\
\text { practices }\end{array}$ & Sheth & 2011 & $\begin{array}{l}\text { Rethinking the core } \\
\text { assumptions of } \\
\text { marketing, such as } \\
\text { market orientation, } \\
\text { market segmentation, } \\
\text { and differential } \\
\text { advantage in emerging } \\
\text { market. }\end{array}$ & $\begin{array}{l}\text { Five key characteristics } \\
\text { of emerging } \\
\text { markets-market } \\
\text { heterogeneity, } \\
\text { sociopolitical } \\
\text { governance, chronic } \\
\text { shortage of resources, } \\
\text { unbranded } \\
\text { competition, and } \\
\text { inadequate } \\
\text { infrastructure. }\end{array}$ & $\begin{array}{l}\text { Journal of } \\
\text { Marketing }\end{array}$ & 241 \\
\hline
\end{tabular}

Notes.Citation data is on Web of Science till October 2018

encoding. These insights provide possible tools for brands which need to communicate certain thematic information with consumers.

Chinese marketing environment gradually became mature with the improvement of the institutional environment and an increasing number of market participants between 


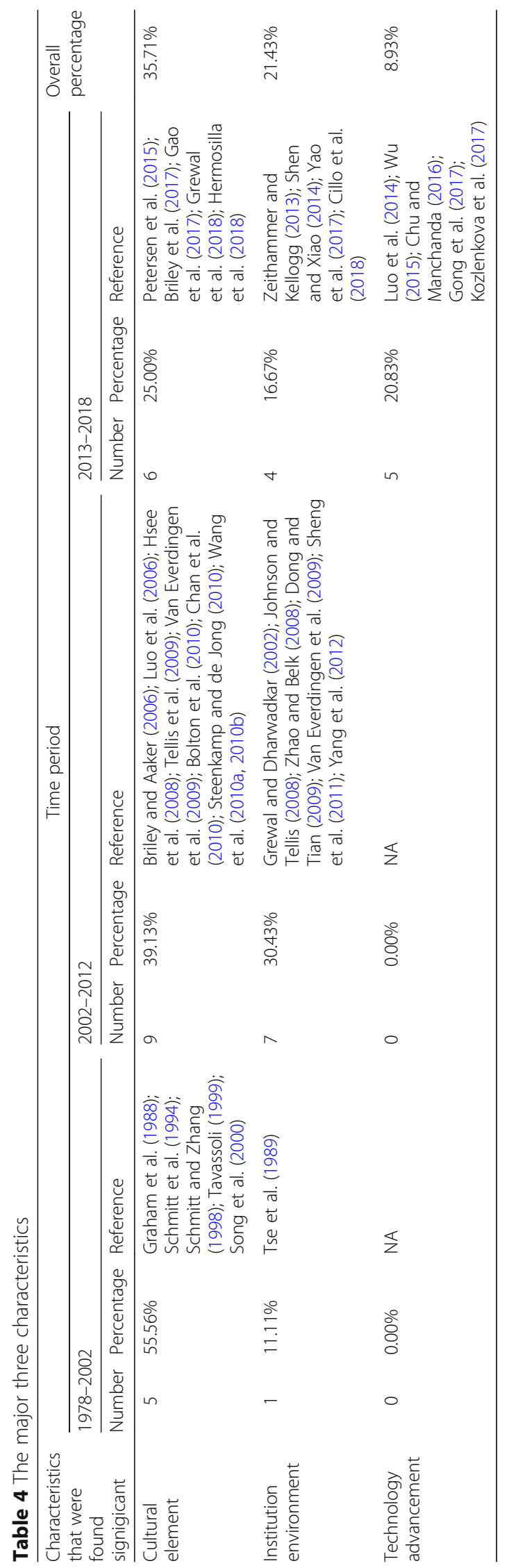


2002 and 2012. Sheng et al. (2011) pointed out that business ties and political ties influence firm performance differently according to the moderating effects of the institutional environment. Business ties are more beneficial when a sound legal system is available. In addition, social capital received much academic attention. "Coopetition" refers to an action which involves cooperation and competition simultaneously. A database which collected data from mid-level managers and top executives in 500 Chinese firms in the high-tech sector has provided evidence that coopetition at the crossfunctional level improves both customer and financial performances (Luo et al. 2006).

As service was playing an increasingly important role in domestic economic activity, the phenomenon of service marketing began to attract academic attention. From the perspective of service providers, frontline employees were facing high pressure at times. Chan and Wan (2012) used a lab experiment and employee-supervisor survey data in the financial service industries to explore the possible effects of work-related stress on employee performance on tasks that require varying levels of self-regulation. The results confirmed that highly stressed employees experienced fatigue and tended to perform poorly on tasks requiring self-regulation. However, they found that this effect could be alleviated by supervisory support or the enhancement of employees' goals.

Research also found that the institutional environment and business climate were improving to correspond with the rising level of business activities. The government, as one of the important participants in the marketization progress, faced issues regarding proper marketing. Countries, cities and regions were usually focused on encouraging more investment, tourism and consumption. However, high level talents are key for the sustainability and continuity of future developments. Scholars conducted research on the "haigui," the people who come back to China from overseas and are generally STEM (science technology engineering and mathematics) doctoral or postdoctoral students who have studied in developed countries (Zeithammer and Kellogg 2013). The research surveyed respondents to estimate their preferences regarding job opportunities as a function of location, job status, and salary.

The digitalization of the marketing environment and practice was the primary characteristic of this period. Social networks had developed rapidly as a marketing tool. Twitter became one of the social network channels used by companies to improve their sale performance. A field experiment was conducted on the TV show market to find the effect of two types of tweets on sale performance (Gong et al. 2017). The first tweets are those posted by the company itself on their TV program, and the others are the re-tweets from influential Twitter users who have many followers. The study revealed that both types of tweets would increase the viewing performance, although the re-tweets by influential Twitter users have a more positive effect if the content of the tweet is informative (Gong et al. 2017). In another study, scholars modeled the growth of the largest customer-to-customer (C2C) e-commerce platform (Taobao.com) from both seller and buyer perspectives (Chu and Manchanda 2016). The model revealed that the sellers' cross-network effect on buyers was larger than vice versa, while the cross-network effect from both sides contributed to the growth of the platform. Wu (2015) also studied Taobao.com and its online advertising system, "Alimama," to reveal two microeconomic mechanisms. A successful online advertising network relies on the advertiser-publisher matching system, which links demand with supply, and the pricing system, which can extract the maximum surplus of the matched transaction between 
advertisers and publishers. The study conducted two counterfactual experiments which showed empirical evidence that a decentralized system such as "Alimama" had a financial performance similar to a centralized full-information platform.

As an early way of digitalizing offline services and products, "group buying" emerged in 2010 and became quite popular after the application "Mei Tuan" was launched and hit its highest growth rate in 2014. Focusing on the fierce competition in this emerging industry, researchers studied the impact of the popularity of group-buying deals on consumer purchasing likelihood and consumer redemption time, which are two key performance indicators for merchants who launch group-buying products or online services (Luo et al. 2014). The results showed that the popularity of deals leads to a greater chance for consumers to engage in group-buying deals and decreases consumers' redemption time.

\section{Consumer behavior}

Culture has been a major focus for researchers investigating the differences in the behaviors of Chinese consumers and their Western counterparts, as well as their underlying mechanisms. Briley and Aaker (2006) conducted comparative experiments on customer persuasion in the US and China. They found that cultural background does not always have a constant, unweaving influence on the consumers' decision-making process. The research found that the subjects of the experiment showed different behaviors based on the length of the decision-making process. When given enough time for careful thinking, individual knowledge and experience played a more decisive role in the decision than when judgements were made in a cursory manner, within a short period of time. The characteristics revealed that Chinese individuals are more easily persuaded by prevention-focused information while Americans respond better to promotion-focused information. Another experiment-based study found that service separation could affect customers' perception of access and benefit convenience, as well as performance and psychological risks (Keh and Pang 2010). In China, traditional medical practices have influenced remedy seeking for most Chinese people. Traditional Chinese medicine is an important medical practice for people in China and abroad. However, the choice between traditional Chinese medicine and Western medicine was a practical issue for many people lacking medical knowledge. Wang et al. (2010a, 2010b) believe that "lay theories of medicine" could affect consumer preference in this regard, when Western medicine became the major medical solution for most people. Bolton et al. (2010) found that culture influences consumer reaction to the prices paid by others for the same products or services, which relates to the perception of price fairness. Moderation effects are extracted by the characteristics of collectivism and individualism held by Chinese and U.S. consumers. The results and data showed that collectivists are more sensitive than individualists when it comes to in-group price differences, while individualists react more to out-group price differences than collectivists (Bolton et al. 2010).

As the level of domestic consumption increased and China became a WTO member, foreign brands became increasingly abundant for Chinese consumers. The Chinese socioeconomic transformation gradually cultivated consumers' needs to build their sense of identity by purchasing foreign brand products. Dong and Tian (2009) asserted that 
Western brands contributed to the evolution of the Chinese national identity based on a selected array of East-West relationships.

Hsee et al. (2013) studied the three-attribute option framework, which consists of magnitude (size of the outcome), time (of occurrence), and probability (of occurrence), and a two-mode evaluation system which includes joint evaluation and single evaluation. The study showed that consumers are more sensitive to all three attributes when they are in extreme conditions and that this nonlinear function is more pronounced in the single evaluation mode. When people are faced with options involving multiple attributes, the time and probability are given higher weight. Scholars found another intriguing fact about the inequity of customer satisfaction in relation to the aforementioned findings about the ways in which people perceive value. Countability, that is, how easily the property of a product or service could be counted through simple numbering, serves as a measure of value. The countability factor moderates the impact of the inequity of satisfaction because the cognitive focus shifts from simple number comparison to the various dimensions of consumption experience (Ma and Roese 2013). This study reveals that the format of the reward could contribute to customer satisfaction. A reward consisting of an experience-based product or service provides a higher perception of fairness. The implications of this research can inform the design of promotion plans to avoid customer dissatisfaction caused by the perception of inequity.

Due to heavy pollution from growing industrial emissions endangering people's health and sustainable development, environmental protection and friendliness have become important issues for nations worldwide. Environmentally friendly consumer behavior could alleviate the degradation of the environment through the evolution of the demand. Scholars noticed a gender gap in "green" behavior. Brough et al. (2016) explained that men's resistance could result from a stereotypical association between "greenness" and femininity. While this greenness gender stereotype persists, men will avoid or even oppose green behaviors. The study explored ways to mitigate this stereotype by masculine affirmation. For instance, marketers aiming to promote greenness to their male clients could affirm muscular traits in their branding strategies.

Comparative studies driven by cultural elements were expanded by several scholars. Petersen et al. (2015) utilized a dataset from a financial institution in the United Arab Emirates to explore how culture affects consumers' financial decisions. This study compared 34 countries, including China. Cultural influencers have direct effects on people's financial decisions regarding savings rate, credit use and spending patterns. The moderating effects of culture on firms' promotion efforts were also tested in the study. Customers with long-term cultural characteristics reacted positively to prevention-focused marketing efforts while customers with low uncertainty avoidance reacted positively to promotion-focused marketing efforts. These culture-related insights can contribute to the design of efficient communication plans that take customers' cultural background into consideration.

At the local level, global brands aim to reduce customers' sensitivity about prices. However, accomplishing a global-to-local strategy might require more resources and time, which makes it economically inefficient. Gao et al. (2017) pointed out that firms do not have to devise strategies to localize, but should change their communication methods to activate customers' local identity. This strategy could achieve the same results, and effectively lower customers' price sensitivity due to the mediating role of the sacrifice mindset. 
Mindset can influence people's health, especially when it comes to recovery after serious health challenges (e.g., cancer, blood-related illness and traumatic injuries). Briley et al. (2017) explained the factors that help consumers cultivate optimism with the mediation effect of framing mode and the moderation effects of cultural background. The research was based on six experiments on single and cross-country samples from China and the US. It provides evidence that people are more likely to be optimistic when they are capable of imagining the recovery process. This process is determined by the matching framing mode (initiator or responder) and culture.

\section{Marketing strategy}

The selected array of strategy papers mainly covers new product development and cultural differences in organizational behaviors. Conflict-handling behavior between managers during new product development is important as an asset to a firm because the knowledge sparked during the handling of the conflict is helpful for new product development. Scholars began to build conceptual frameworks targeting the antecedents and consequences for such behavior (Song et al. 2000). Cross-cultural data were collected from four different cultures, including Hong Kong as a representative of Eastern culture. Song et al. (2000) separated the conflict-handling behaviors of marketing managers into two categories: avoiding and collaborating conflict behaviors. The empirical results demonstrated that effective integration should be promoted by decreasing conflict-avoidance behaviors and increasing collaborating-conflict behaviors. Literature about new product development was expanded to a multi-national level. Factors which were theoretically proved to have an impact and are related to the market, products, the product development process and organizations, are tested under the same model using data from the US and China (Calantone et al. 1996).

Cultural backgrounds also play a significant role in influencing managers' behavioral traits. Therefore, scholars have conducted experiment-based comparative studies in a laboratory simulation to investigate the differences in buyer-seller negotiation between the Asian and U.S. cultural contexts (Graham et al. 1988). For this research, the information exchange process investigated was limited to face-to-face negotiation. Results showed that the strategy has diverging performances in different cultures. Specifically, a competitive strategy works more efficiently in Eastern culture while a problem-solving strategy helps improve negotiation outcomes between U.S. counterparts.

Field experiments were the chosen research methodology to tackle Chinese marketing inquiries. As for studies on pricing strategy, Hsee et al. (2008) explained the inconsistency between the goals of pricing strategies planned beforehand and their actual outcomes with a field study in the Shanghai real estate market. The study leveraged the prominence principle to identify a conflict between real estate developers' price-matching methodology and consumers' decision-making process when it comes to actual purchasing. The results showed that, when dozens of attributes are considered before buying a housing unit, the choice of a better floor becomes a higher priority than a lower price. The underweighting of the floor factor by real estate developers contributes to the "flat selling pattern" in the planning and the "good sells faster than bad" pattern in the final result (Hsee et al. 2008). In addition, as a commonly used pricing and promotion strategy, discount is often used by marketers. Yao et al. (2012) proposed a strategy to identify discount rates 
which could assist the literature of consumer behavior, drawing on the trade-off between short-term and long-term goals. The outcome of the strategy made it possible to estimate the accurate matching performance with the actual discount rate.

As for the strategies regarding distribution, the observation of a joint sale program launched by an international food company in China helped researchers examine distributors' varying motivations during the joint program. Gu et al. (2010) postulated and tested the hypothesis that distributors' ex ante commitments are driven by loss avoidance while the ex post adaptation reflects distributors' rent-seeking motivations. While online business and commerce were becoming routine, new practices regarding traditional department stores emerged during this period. One of these practices is the store-in-store arrangement, which refers to major brands setting up "boutique stores" in large retailers such as Macy's in the US and Wangfujing department stores in China. Scholars thus built an economic model based on this store-in-store practice (Jerath and Zhang 2010). The model captures the economic incentives of inter-brand competition and double marginalization. It gives insight into the decisions made to bring more store traffic and therefore increase the overall revenue for retailers. The retailers face a tradeoff between channel efficiency and inter-brand competition, in which the degree of autonomy given to manufacturers and the maneuvers of the retailer would help adjust the overall performance (Jerath and Zhang 2010).

New marketing concepts and practices were also investigated. The notion of customer participation (CP) was devised in the early 2000s as a new marketing frontier to enhance corporate competitiveness by means of learning and engaging customers' dynamic needs. This innovation marked a shift from a product-oriented logic to a service-oriented one (Vargo and Lusch 2004). Empirical evidence based on data from financial institutions in China (Hong Kong) and the US was used to show that CP could be a "double-edge sword" for firms aiming to promote value co-creation through CP (Chan et al. 2010). The research suggests that CP could provide positive effects and fulfillment to customers while causing more pressure on employees, which might harm employees' job satisfaction. Culture was found to have influential effects on value creation through $\mathrm{CP}$. Therefore, marketing decisions regarding $\mathrm{CP}$ could be made more effectively by matching customers' and employees' cultural backgrounds. As start-up companies began to thrive, China was becoming one of the "emerging nations" in the research of radical innovation. In an analysis of a Chinese sample, corporate culture was found to play an increasingly important role in forging radical innovation, in contrast to factors found to be relevant in prior research findings, such as national labor, capital and culture at the macro level (Tellis et al. 2009).

Discount is not always a good choice for a promotion strategy. Cai et al. (2016) illustrated this boomerang effect through the lens of purchase value theory, which argues that consumers' purchasing propensity is lower when a low discount is offered on nonessential products, and higher when the same discount is given on essential products. The mechanisms are bridged by perceived acquisition value and transaction value, which are different for consumers who are making decisions regarding essential and nonessential purchases.

TV commercials remained the most effective advertising tool to reach general households in China. Around the end of 2011 and the beginning of 2012, commercial breaks in the middle of TV programs were banned. This worked as an exogenous shock to the 
TV industry. Scholars observed the TV viewers' behavior before and after the new regulation as a natural experiment to propose a search model for different types of TV viewers. The results shed light on the strategic choices of TV channel operators when choosing commercial breaks for better advertising performance. Channels with low viewer ratings could protect their viewership by synchronizing with highly rated channels so that TV viewers would be less likely to change channels. On the contrary, channels with high viewer ratings could boost their competitive advantage by providing better TV programs when their competitors would be broadcasting commercial breaks (Yao et al. 2017).

In a digital environment enabled by real-time connection, one of the emerging marketing forms is theonline relationship marketing. Online-shopping has become an important purchasing way for most Chinese consumers, and the online-shopping market in China is extremely large. Scholars conducted experiments to test the performance pay-off of different types of online relationships and evaluated the effects of several online relationship formation strategies. Kozlenkova et al. (2017) indicated that various types of online-relationships help customers decrease shopping risks. More specifically, the reciprocal relationship has been found most effective in performance pay-off in comparison to a unilateral relationship that is initiated by a community, seller or buyer (Kozlenkova et al. 2017). Another form of e-commerce for offline stores and restaurants is to utilize applications that transmit information about the service provider and user-generated word-of-mouth. Jia et al. (2018) used a dataset from a third-party review site in China, which added new insights on the large bulk of price-promotion research. They found different results about the relationship between the face value of coupons and customers' spending when the coupon is focused on a line of products rather than one specific product. Another form of marketing is "cause marketing" also known as $\mathrm{CM}$, CM refers to the donation of part of the revenue from each product sold to a charity organization or cause (Varadarajan and Menon 1988). Scholars used large-scale randomized field experiments to verify CM effectiveness in increasing a firm's total revenue and the inverted- $U$ effect of the moderating effect of price discounts(Andrews et al. 2014).

Product distribution and marketing channel formation face new challenges. In a distribution network, a challenging event not only affects disciplined members but also the observers who might take advantage of the punishment of another channel. Taking the cultural element into account, China provides a suitable research setting for a networkbased view of punishment with a focus on social networks and informal governance, where social relationships are considered important in channel management. Researchers used survey data collected in China to address the effects brought about by a punishment event on observers. Wang et al.'s (2013) study revealed two mechanisms that reduce observer's opportunism: a direct deterrence effect and a trust-building process. A moderating effect is brought by a disciplined distributor's relationship embeddedness which increased information asymmetry, and the manufacturers' monitoring capability which decreases information asymmetry . Scholars examine marketing structures on the interfirm level when plural structures, i.e., multiple participants such as suppliers or buyers, were increasingly employed in business practices in the 2010s. Fang et al. (2016) investigated the relative effects of learning and found a dependence-balancing mechanism between a dyadic marketing structure and a plural marketing structure. This study revealed 
that the plural structure performs better when the alliance is made in a growing industry or when the upstream firm has more alliance experience. The dyadic structure works better when the upstream firm is more competitive (Fang et al. 2016).

Studies also involved marketing practice and theory at the business-to-business level. Using a dyadic dataset of a large Chinese information system service provider and its major business customers, Wang et al. (2017a) examined customization from the perspective of the supplier. The research presented a dilemma caused by the customization of services or product providers which involves the increase of both cost and revenue. The contingency mechanism has been moderated by four factors: customer demand ambiguity, product modularity, project team technological ability, and relationship embeddedness. Using these moderators, boundary conditions are found between project customization and suppliers' financial performance comprising cost and revenue. (Wang et al. 2017a).

\section{International marketing}

Thanks to a more active opening up policy for international trade and business, a sharp rise was seen in the number of foreign firms doing business in China and an increasing number of Chinese firms seeking opportunities overseas. An emerging market like China was a key battleground for international firms to gain influence and obtain a greater share of the global market. Johnson and Tellis (2008) explored the causes for a successful market entry into China and India and counterintuitively concluded that smaller firms have a better chance of entering emerging markets than larger firms. The other counter-intuitive conclusion was that entering a market that was more open to foreign firms was less likely to be successful. More surprisingly, India had a significantly lower success rate of entry than China (Johnson and Tellis 2008). Arrangements and pilot regions, like the special economic zones in Shenzhen and Shanghai, provided academic opportunities to study the interaction between the institutional environment and international entrants' marketing strategies. In the beginning of 2002, international marketing channel researchers started to explore channel attributes, behaviors, and structures from the perspective of legitimacy rather than efficiency. They highlighted the influence of the institutional environment on the marketing channel and proposed a conceptual model which considered institutional environment as an important factor (Grewal and Dharwadkar 2002). At the time, China was building economic pilot zones where policies regarding tax, market entry and foreign investment were favorable for multinational corporations (MNCs) seeking development in China. Grewal and Dharwadkar (2002) proposed that, when the inducement given by the government is favorable enough, MNCs might grow dependent on these inducements and take recommendations from the government on their channel management.

Joining the WTO brought unprecedented opportunities for Chinese firms to do business overseas, but cultural and administrative barriers impeded a better internationalization. Usually, these "going global" firms had to pay in terms of market performance for gaining social acceptance overseas. Scholars found that the situation could be alleviated with governance strategies such as inter-firm governance strategies and the customization of contracts (Yang et al. 2012). Around 2008-2009, during the global financial crisis, China's domestic economy remained resilient, which contributed to business opportunities for domestic firms entering developed markets. Foreign goods and brands gradually became available to Chinese 
consumers in large quantity and across various categories. Chinese manufacturing firms that were competitive because of their low labor-cost advantage were seeking market opportunities overseas. This led to brand naming becoming a marketing problem for both Chinese firms and their foreign counterparts. Zhang and Schmitt (2001) expanded the research regarding brand naming in English into the international and multilingual market of China. This study revealed that choosing the appropriate translation method might help marketers improve branding performance in China. The study provided empirical evidence that suggests the careful consideration of linguistic and geographic factors which might affect consumers' mental perceptions (Zhang and Schmitt 2001). During this period, many Chinese firms were aware of the entry of products from developed countries such as the US, Germany and Japan, which generally represented better quality and durability for consumers. Thus, some domestic firms aimed to become "global brands." The naming of a brand thus became the first step, such as in the case of the two major electronic appliance manufacturers, Glanz and Haier. Scholars found that the incongruency between the actual country of origin and the implied country of origin decreases the likelihood of purchase. This correlation was found to be more significant for hedonic products (Melnyk et al. 2012).

Market attractiveness of new products in foreign countries for international companies is based on two factors: market potential and penetration rate (the speed at which a new product could be diffused). Talukdar et al. (2002) conducted comparative studies, which reported that developed countries have a higher penetration rate for new products. Their study also points out that the macroenvironmental variables such as the level of international trade and urbanization that is changing significantly-especially in China-can have a positive effect on new product penetration at different rates. Van Everdingen et al. (2009) further enriched the modeling literature on new producttakeoff in overseas market by considering the economic, cultural and geographic distances between countries as moderators. Drawing on the "global vs. local" debate, scholars also tried to discover the underlying motivational structure contributing to the different attitudes among customers towards global or local products ("AGP" or "ALP"), and the relationship between them (Steenkamp and de Jong 2010). Hermosilla et al. (2018) explored the impacts of consumer preferences on global product design in the emerging markets through a study of the influence of the Chinese audiences' preference regarding actors' skin color ("colorism") in Hollywood casting. Instead of the "test grounds" of the developed markets, the rapid Chinese economic development and the newly endowed customers with increasing purchasing power could become the first order mover to set general preferences on a global scale.

Building a marketing channel is a key strategic factor for firms doing business overseas. Therefore, scholars have adopted new perspectives with the help of metatheory to propose new relationships and constructs that could be added to the pertinent framework of determinants of the international marketing channel. One of these constructs originated from the practice in China. MNCs sometimes lobby for institutional change for channel building, maintenance and management, and a foreign firm might play an active role in ushering an attribution law revision (Wilson 2008). A new construct of "institutional pliability" defined the extent to which an institutional domain is open to the influence from MNCs (Grewal et al. 2018). At the inter-firm level, Shen and Xiao (2014) studied the entry and chain opening decision 
made by two major Western fast food giants, McDonald's and Kentucky Fried Chicken (KFC), to test two driving forces that could have positive effects on a rival's development in a foreign market. The first, market learning, included information about the potential investment value of opening a chain within a given area that is provided by a rival's entry to a new region. The second, demand expansion, refers to the expansion of the rival, which might help cultivate the demand for products or services in the same category.

\section{Review findings from Chinese journals}

In this section, we introduce findings from Chinese journals in two steps. First, we show the general pattern of our sample papers. We provide yearly publications statistics and the major research themes. Second, we discuss some influential papers by themes.

The first marketing paper in our sample is an article published in Management World in 1985 which focused on the exploration of customers' routine behavior (Hua 1985b). Figure 1 shows the publication status of three Chinese journals from 1978 to 2018. The shaded area represents the proportion of each journal in the sample.

The volume of academic papers published in the field of marketing has grown rapidly in China since 1998. There was a sharp rise in the number of paper published in Nankai Business Review in 1999 and 2000. If we do not include the papers published in the Journal of Marketing Science, which is a marketing-oriented journal first issued in 2013, the number of publications in our sample reached its first peak in 2010. Figure 2 depicts the overall publication status for three time periods: 1978-2001, 2002-2012 and 2013-2018. The number of papers published between 1978 and 2001 was 84, which accounted for $11 \%$ of the overall sample. The publication number for the following two time periods were 326 (41\%) in 2002-2012 and 379 (48\%) in 2013-2018. A mild increase in marketing publications was observed.

We combined related keywords in categories. For instance, "customers," "perceive," "customer loyalty," and "customer satisfaction" were all identified in studies concerning customer behavior. The top categories identified were: "consumer behavior," "international study," "modeling," "strategy," "brand" and "technology." Figure 3 shows a general proportional change of each field from 1978 to 2018. Figures 4, 5, and 6 depict the composition of the research fields in each time period.

From a temporal perspective, studies regarding consumer behavior or consumerrelated studies are the most covered topics in Chinese marketing literature. It represented 34\% of the research papers from 1978 to 2001, and 43\% and 44\% respectively in the following two time periods.

International marketing study first appeared in 1998 in the Nankai Business Review.A declining trend has been seen over the recent years. The percentage of international studies were $3 \%$ after 2001, when China successfully became a WTO member. Modeling became a consistent research means after the first paper on this topic was published in 2000. The proportion of modeling papers increased to $14 \%$ from 2002 to 2012 and kept in 11\% during 2013-2018. Another declining research theme was strategy. It was first explored in 1999, and made for $21 \%, 9 \%$ and $4 \%$ of the marketing publications in each respective time period. Brand research was first conducted in 1999 and consistently made for around 20\% of marketing publications 


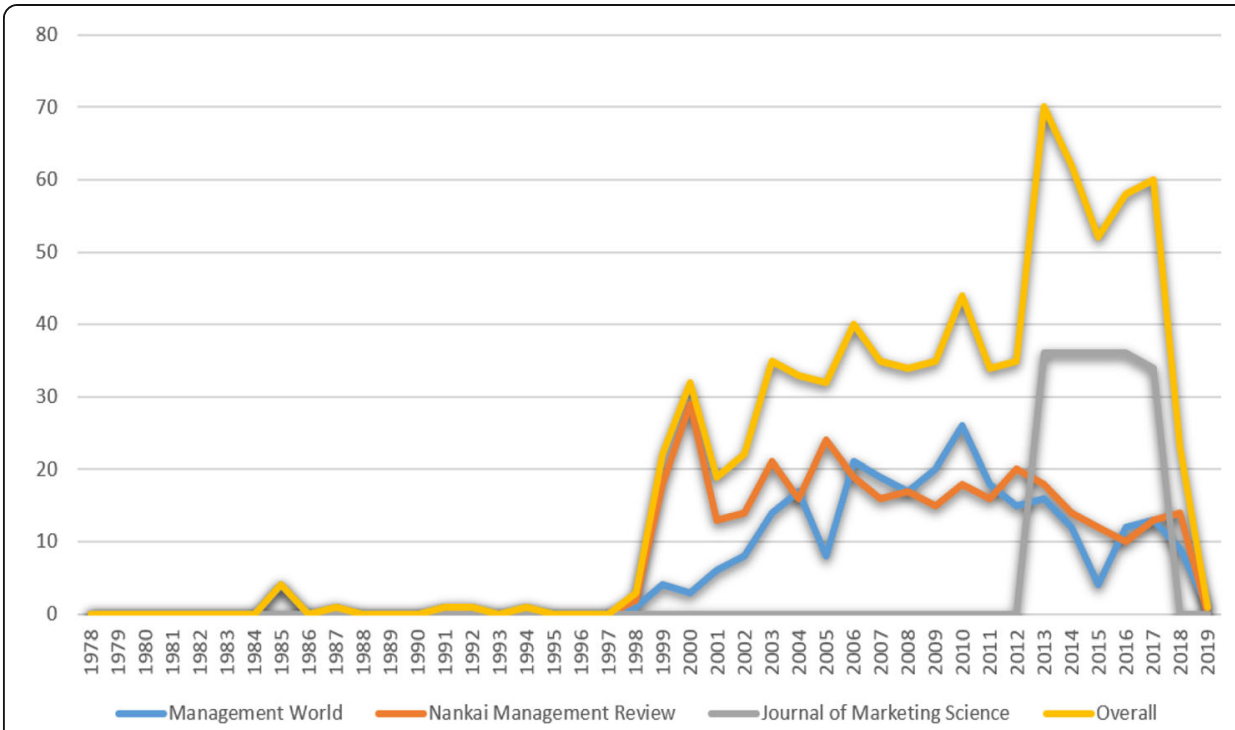

Fig. 1 Variation of publication status of three Chinese journals from 1978 to 2018

over the years. It fluctuated within $+/-3 \%$ over the entire 40 -year time period. We can observe an early focus on technology advancement from Chinese marketing scholars. The first technology-related paper was published in 1992 but technologyrelated topics became less popular between 2002 and 2012, before regaining momentum after 2013.

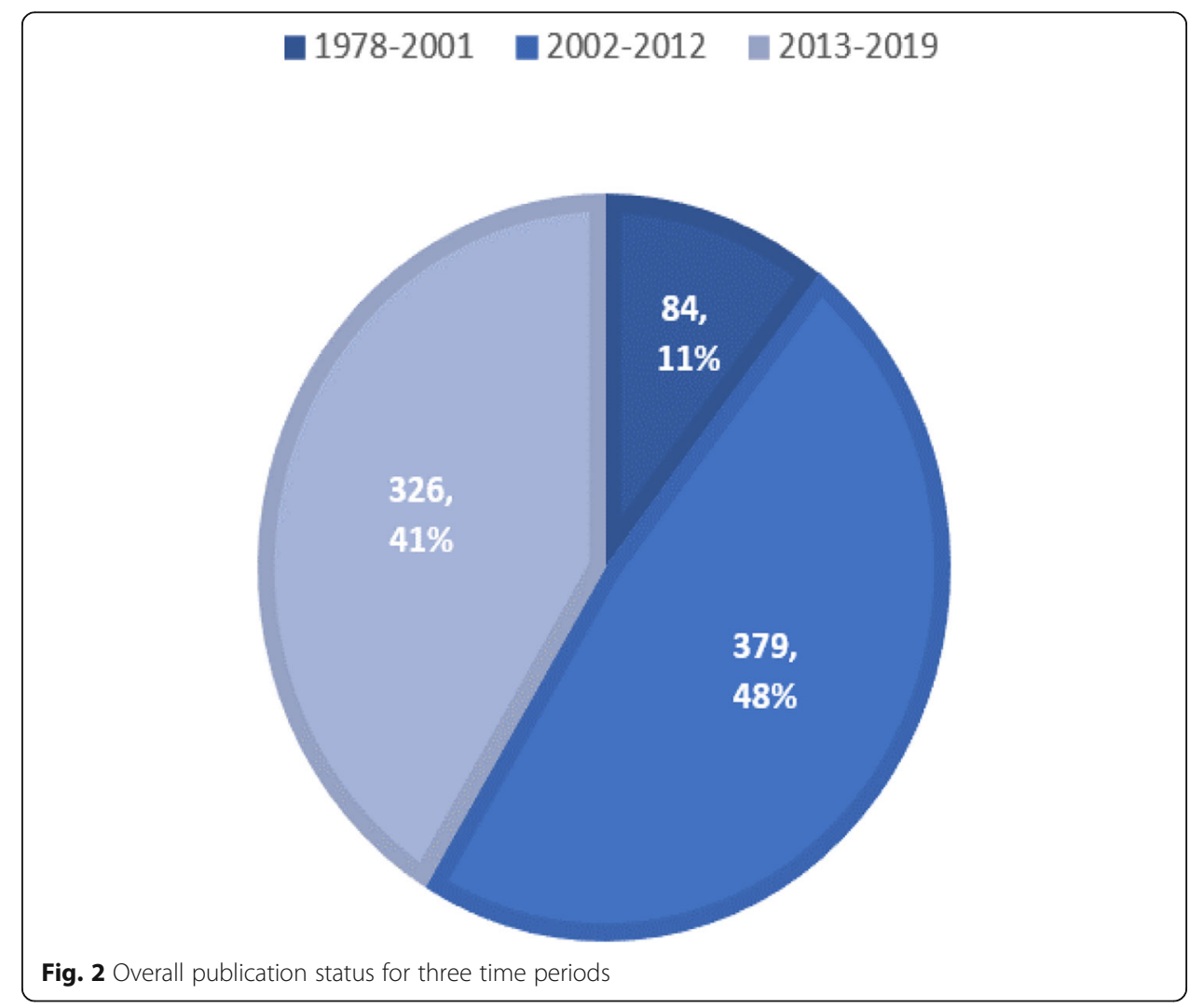




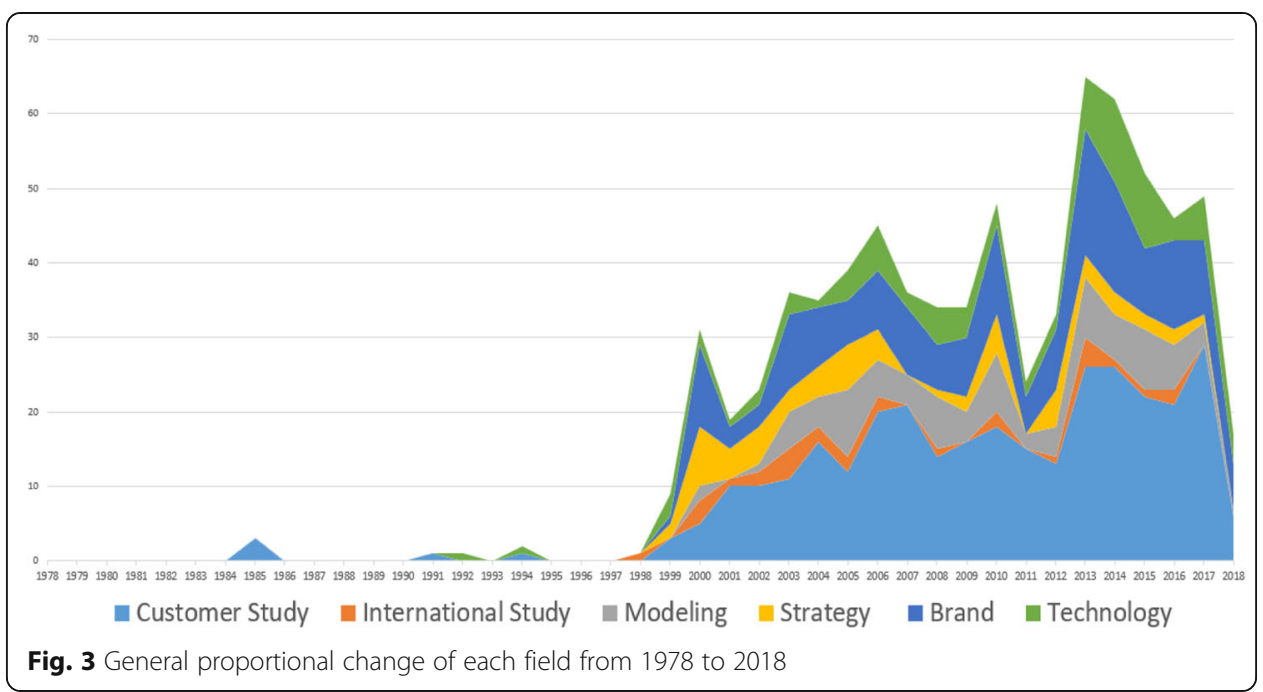

\section{Customer-related studies}

The earliest literature on customer-related studies date back to 1985, when a set of customer qualitative studies about psychological characteristics of consumers (Hua 1985a) and customer traditions (Hua 1985b) were published. Most of the customer-related research during this early moment of marketing research were qualitative or theoretical studies. The purpose of the studies was to lay the theoretical framework or foundations for customer studies.

Customers' intention to buy and purchasing behavior Customers' intention and purchasing behaviors were explored in various contexts. Li et al. (2010) studied the impact of a sudden accident on customers' purchasing behavior. As online-shopping was becoming common for Chinese customers, scholars explored various factors that affect customers' purchasing behavior, such as image display, psychological clues, and feeling

\section{8-2001}

Customer Study $\quad$ International Study $\quad$ Modeling

Strategy

Brand

Technology

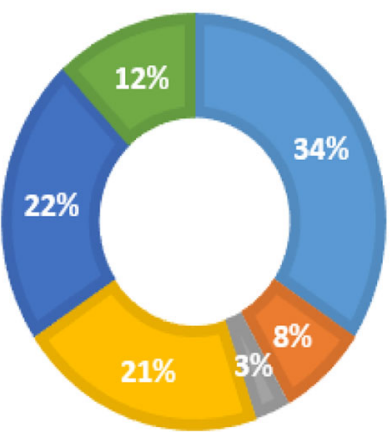

Fig. 4 The composition of the research fields in 1978-2001 


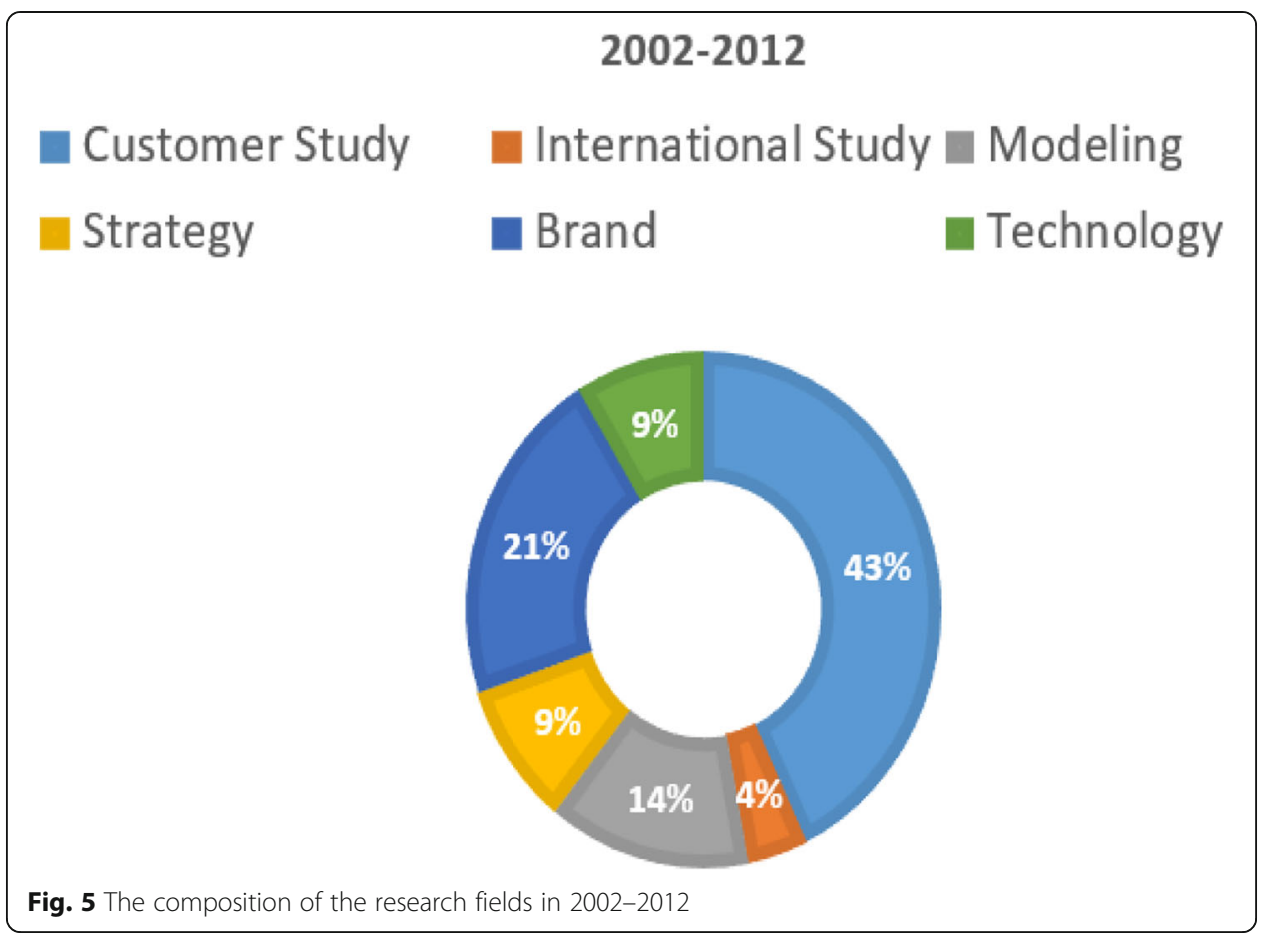

or touch clues in online comments. Scholars also studied how different types of products and initial conflicts in purchasing decisions would impact customers' intention to buy (Wang et al. 2017b). When customers have similar social identities to the online commentators for the focal product, they tend to have a stronger intention to buy (Hong et al. 2017). Li et al. (2016) pointed out that family-like relationships between a customer and service employees would also foster customers' intention to buy. Other factors like business's reputation and corporate social reasonability (Ma 2011) could also affect customers' intention to buy (Wang et al. 2007).

Customer satisfaction and customer loyalty Han and Wei (2001) defined customer satisfaction and customer loyalty and explored the irrelationship. Other concepts such as customer experience and perceived service quality have also been investigated. Wang et al. (2003a) empirically tested customer satisfaction and its effects on customer loyalty. Customer loyalty has been revisited by a meta-study with a detailed breakdown (Fan et al. 2009). Huang et al. (2014) explored the paradox between customer professionalism and customer loyalty within the context of the financial service industry. This study showed that more customer education might not develop more customer loyalty. Customer professionalism has different mechanisms towards attitudinal loyalty and behavioral loyalty. In addition to the aforementioned studies regarding customer satisfaction and loyalty, there are also studies which examined more complex mechanisms. Lu (2007) explored the moderation effect of industrial competition and customer characteristics between customer satisfaction and customer loyalty. Jin (2007) investigated the mediation effect of perceived risk and value between service warranty and customer satisfaction.

From the perspective of methodology, new research techniques on artificial neural networks used to study the impact of service characteristics on customer satisfaction 


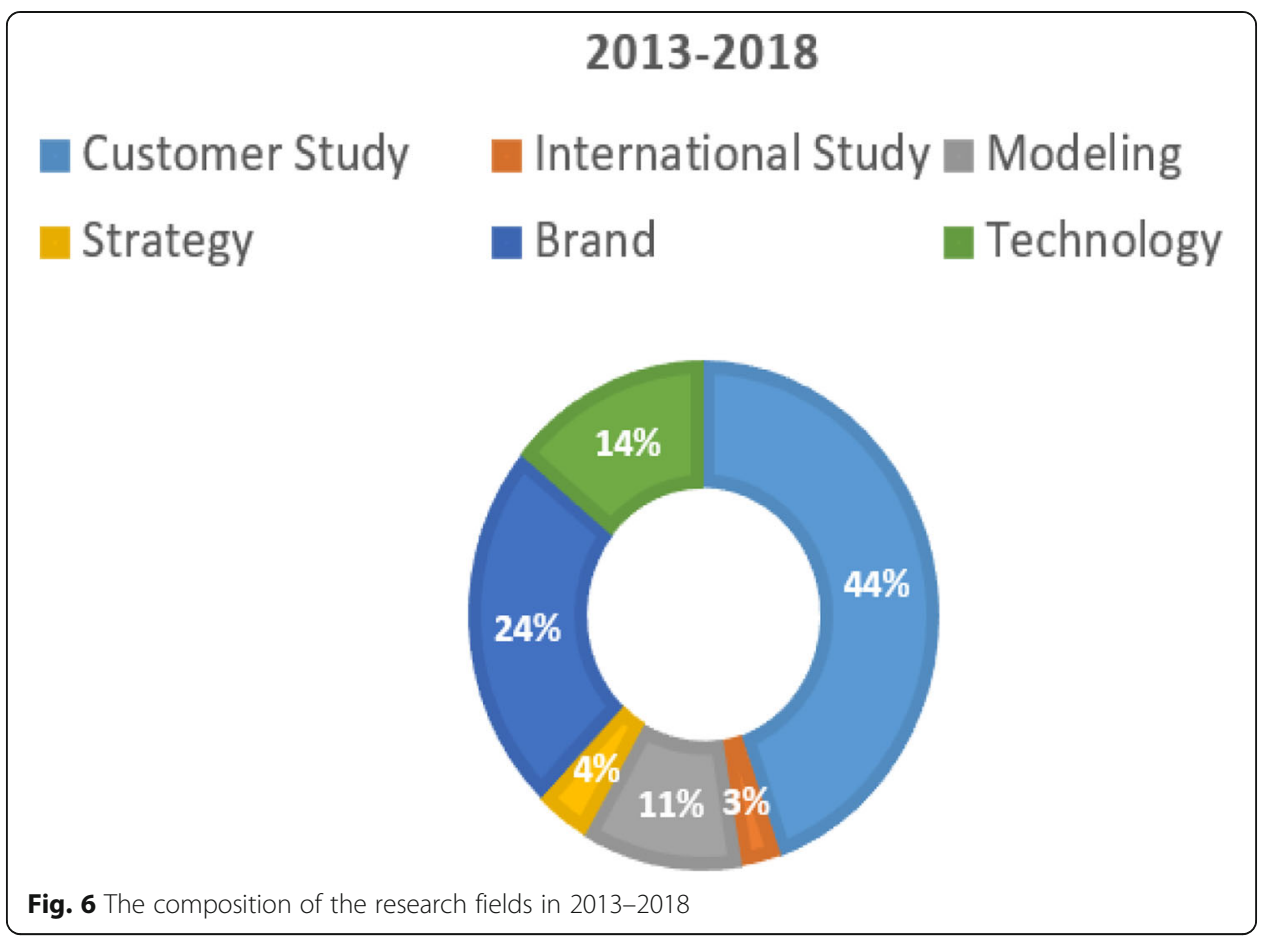

were introduced by Cen and Quan (2005). This study pointed out that neural networks can better predict customer satisfaction in the hotel business than regression.

Customer value and customer relationship management The concept of customer value was studied at the beginning of the new millennium. Yang and Wang (2002) discussed customer value and its driving factors. Other studies focused on the empirical evaluation of customer value (Wang 2005) and its role in forging a competitive advantage. Pan et al. (2014) developed a scale for measuring customer values within the context of Chinese culture. Value co-creation emerged from the field of customer relationship management, wherein researchers explore the effects of customer value cocreation on brand assets considering the mediating effects of brand experience ( $\mathrm{Li}$ et al. 2014). Moreover, drawing on the value co-creation perspective, Pu et al. (2017) explored the mechanisms of customer experience and customer loyalty. Scholars also examined the detailed mechanism of this co-creation process.

Customer relationship management is a broader topic than value exchange. Drawing on the basic concepts, Wang et al. (2008a) addressed the capability of customer asset management and its composition. Luo and Fan (2005) studied the mechanism of relationship marketing through the theoretical lens of psychological contracts. Tang et al. (2007) compared the investment in customer relationship and price promotion in the hotel industry. They found that building relationships with customers could be more effective than offering price promotion. Studies were also undertaken on concepts related to customer relationship management within service marketing, such as customer retention and service failure.

Customer behavior in the Chinese context There are a few studies focusing on the unique characteristics of Chinese customers. Wu and Qiu (2007) found that urban 
consumers' motivation to consume and their preference for chain-stores do not apply to customers in rural areas, which indicates the importance of demographical factors. $\mathrm{Su}$ et al. (2013) revealed that Chinese consumers from different regional backgrounds display different value systems and different purchasing styles. Drawing on Chinese cultural elements, Wang and Gao (2013) proposed a customer relationship model based on the Confucian value system.

\section{International marketing studies}

Competitiveness In our sample papers, most international business studies are oriented toward customer studies, modeling, branding and strategy. However, some of the papers are highly focused on international themes, such as the competitiveness of foreign entrants and domestic companies. Wang (2000) analyzed the formation process and influential factors of international competitiveness. Zhang (2003) discussed how to improve the international competitiveness of Chinese firms.

International strategy Scholars explored the strategic decisions of successful multinational firms in different industries to provide managerial references for domestic firms. An increasing number of Chinese firms built international businesses and subsidiaries, leading scholars to discuss strategic planning and the domestic impact of these companies (Wang 2014). Wu and Yuan (2003) introduced the integrated global marketing strategy (IGMS) model and discussed its implication for Chinese companies seeking multinational coverage. Grounoos and Sun (2001) introduced five independent internationalization strategies for service companies. Moreover, scholars proposed solutions for practical trade problems; for example, $\mathrm{Xu}$ (2000) addressed the obstacles in the China-Europe textile trade and offered international marketing strategies.

\section{Modeling}

The academic efforts regarding modeling generally involved building conceptual and empirical models.

Theoretical model Li and Wang (2006) suggested improvements to the traditional marketing mix model of 4Ps (product, place, price, and promotion). Wang et al. (2007) explored the marketing model for digitalized products within the online environment. Pan et al. (2005) examined a new model with 8Rs (regal, romance, reward, rarity, retention, radiance, renewal, and respect) for fostering a world-class brand. In addition to general marketing models, specific marketing theories also received academic attention. Yang (2000) proposed an integrated conceptual model to understand the behavior of marketing channel partners. Li and Liu (2004) offered a general model for market positioning strategy. Xue and $\mathrm{Yu}$ (2003) introduced a conceptual model capturing brand extension through asset value transfer. Liu and Jin (2002) proposed a strategic marketing model based on consumer demands and information search processes. Wang et al. (2010a) analyzed the innovation process of the financial service. 
Empirical modeling The papers on empirical modeling were mainly focused on three streams. The first stream was concerned with constructs measurement or index system building. For example, Fu (2004) explored a model to evaluate the brand value and Chen et al. (2005) created an association network based on a brand positioning evaluation model. Liu et al. (2003) attempted to build a novel customer satisfaction indexing model with SCSB, ACSI, and ECSI analysis. Wang et al. (2008) modeled the relationships among market orientation, customer asset orientation and the performance of new product development with Chinese contextual moderators.

The second stream aimed at quantifying the phenomenon or dynamics in marketing practice. Xie and Zhao (2005) introduced a formative model for measuring customer satisfaction. Zheng and Huang (2010) proposed a model characterizing the free rider phenomenon in supply chain management. Wang et al. (2012) explored the interaction progress of Internet word-of-mouth based on reply behavior with a layered Bayesian selection model. Han and Li (2012) proposed a layered psychological authorization model based on customers' desire for control.

The last stream focused on the performance evaluation of strategic decisions. For example, Xu et al. (2004) investigated a model offering implications for firms in customer satisfaction strategies and Sun (2016) modeled competing manufactures' product selection and marketing decision-making.

\section{Strategy}

General strategic studies and strategic planning This stream of strategy papers focused on the different marketing strategies implemented by firms to stay competitive. Scholars began to explore strategic themes such as consumption-based differentiation, segmentation strategy, and positioning. Yang (2001) discussed strategic planning for firm development and competitiveness within the context of a dynamic operating environment in which three types of development strategies could be implemented either individually or in combination. Li (2001) proposed strategies for value chain improvements. In their case study, Qin et al. (2010) provided evidence that a cost leadership strategy could be combined with differentiation strategy in Chinese business practice. Liang and Tan (2005) coined the concept of business ecosystem and explained the embedded value system. The theme of business ecosystems was revisited by Wang (2016) for future discussions about the business model, innovation and business ecosystem design. Wang et al. (2003b) empirically explored the ingredients for the improvement of dynamic competitiveness for Chinese firms. Using data from Taobao.com, Xue and Guo (2012) investigated the competitive strategy of e-business sellers on consumer-toconsumer platforms.

Brand strategy Liu (2000a, 2000b) discussed brand growth strategies for international firms and Zheng (2000) further elaborated on the scientific meaning and general mode for building famous brands. In the context of internationalization, Guo et al. (2012) explored branding strategies after an international acquisition. Li et al. (2013) investigated the relationship between original equipment manufacturers' (OEM) special investments, competitive priorities and brands' individual strategies. 
Technology

Business in the digital environment Yang (1998) first discussed the marketing revolution that could result from the thriving of Internet. As for trust mechanisms in the digital environment. The concept of relational benefits in relation marketing was revisited within the online context by Cui et al. (2006). Through a case study, Xiao et al. (2014) proposed a dynamic capability model which involved a co-evolving dynamic capability between electronic commerce companies and their customers.

Consumer behavior in the digital environment Li et al. (2014a) studied the mechanism of e-service environment on customer behavioral intention based on the concept of initial trust. Based on evidence from online brand communities, Hu and Guo (2013) investigated customer behavior in mobile Internet with the sandglass model.

Online comments and word-of-mouth Wang et al. (2017c) examined the effectiveness of online comments to explain different types of consumers' purchasing decisions and respective boundary conditions. This study shed light on managers' choices. Using data from a popular mobile application (Da Zhong Dian Ping), Zhang et al. (2014) estimated how different characteristics of online word-of-mouth (WOM) would affect customers' online behavior. Wang et al. (2015) investigated the effect of online service recovery on customer electronic WOM.

\section{General discussion}

In our review of the sample papers, cultural influencers and the institutional environment are two highly important research themes, in sharp contrast with research originating from a Western cultural context. Cultural elements play a significant role in Chinese marketing research, both from the customer and the marketer perspectives. For customers, cultural differences are reflected in customers' cognition and processing of marketing information (Schmitt et al. 1994; Schmitt and Zhang 1998; Tavassoli 1999), purchasing decision-making, or financial decision-making (Petersen et al. 2015). Simultaneously, the Chinese culture and its long history have created beliefs that affect customers' overall preferences (Wang et al. 2010b). Compared to Eastern culture, the mindset and psychological processes in Western culture are different and certain emotions, such as optimism, are elicited by different triggers in different cultures (Briley et al. 2017). As for marketers, cultural background can induce different mechanisms in manager behaviors such as conflict-handling behaviors (Song et al. 2000) and buyer-seller negotiation (Graham et al. 1988). In China, cultural elements also proved influential in creating moderating or mediating effects in cooperation mechanisms (Wang et al. 2013), marketing network structure within inter-firm levels (Fang et al. 2016), and stock price and innovativeness (Cillo et al. 2018). For foreign entrants, consideration of the cultural traits of target customers when naming their brand in China is another factor that has been studied (Zhang and Schmitt 2001).

Culture and institutional environment are highly intertwined. In the 40-year process of economic reforms and opening up of the market, the institutional environment was another profound factor influencing how domestic firms and their foreign counterparts were doing 
business in China. The underdeveloped laws and regulations caused the timing mismatch between a step-by-step institutional environment building process and the fast-pace marketing development created issues for marketers and increased firms' costs in certain marketing activities (Jayachandran et al. 2013). An informal governance mechanism was leveraged based on the unique culture of social bonds in China, especially when it came to political and business ties, which had positive effects on coordinating marketing activities when the marketization was in its early development phase (Jayachandran et al. 2013). Based on this mechanism, the institutional environment and its development status determined some of the firms' focal resources, such as political ties, which had a significant impact over firms' performance (Sheng et al. 2011). For foreign entrants, the institutional environment is a key ingredient when MNCs make decisions about their target market. Compared with other emerging markets, China was more attractive in its institutional settings for foreign investments owing to its improving infrastructure, which in turn fostered a higher entry rate for foreign companies (Johnson and Tellis 2008). Furthermore, favorable policies and institutional environment characterized by pilot policies in Chinese special economic zones caused MNCs' growing dependence (Grewal and Dharwadkar 2002). However, revisions in the laws also occurred because of MNCs' lobby (Wilson 2008).

\section{Future directions for research}

In the following subsections, we propose several possible future directions for marketing endeavors based on the current state of marketing practice and the current shifts in the overall environment.

\section{Direction 1: The shift in the marketing environment and consumer behavior evolution in China}

Fueled by technological advancement and the growing purchasing power of Chinese consumers, the general marketing environment and consumer behavior are changing rapidly. This evolution offers researchers unexplored themes for further inquiry in the evolution of Chinese customer behavior and the shift of the marketing environment.

Generally, the effect of the one child policy has led the Chinese population into an era of aging, which causes medication and health concerns to be increasingly important, both at the macro level for state policy makers and at the micro level in each household. Aging consumers motivate a large health-related market involving a larger number of firms and practitioners. This market has the potential to engage with effective marketing strategies and practices that can respond to the authentic needs of the general public and create business value while improving the health status of the country. The communication plans for consumers could have a key impact and alter the status quo, as problems related to fake drugs and tensions in doctor-patient relationships must be solved. Gender maintenance and gender stereotypes could be used by researchers as starting points to focus on gender traits that facilitate certain consumer behaviors as well as on the common stereotypes or prejudices that might prevent one gender from showing certain behavioral tendencies. Such research would involve confirming existing stereotypes and underlying associations, such as greenness and femininity (Brough et al. 2016), and linking them with focal marketing phenomena. This research topic could be undertaken with a reverse perspective on gender maintenance 
and stereotypes, since Chinese consumers are becoming more inclusive and openminded in their behavior toward gender identity.

\section{Direction 2: Marketing strategies in a digitally enabled and data-rich context}

Promotion is becoming increasingly convenient and complex in a digitally enabled and data-rich environment. Attracting customer attention is becoming more difficult as consumers are constantly solicited by commercial content and key opinion leaders (KOLs) on multiple channels. Studies drawing on customer demand estimation and advertising could be inspired by previous research on commercial break timing (Yao et al. 2017) to explore the effectiveness of planning commercial times within internet-based content distribution platforms. In this novel environment, most programs are available on smartphones or tablets which have become common mediums to view and distribute advertising content. Although the emerging strategies and practices empowered by technologies such as mobile networks, the internet of things (IoT) and big data are key advantages for marketers, offline channels are still vital to build a vibrant brand image and deliver high quality services.

Governance strategies to regulate resource allocation between various e-commerce platforms and sharing economy platforms are needed, both for newly launched applications and established giants like Alibaba and DiDi. There exist major differences between these platforms and traditional product or service suppliers whose concerns are only to fully satisfy their customers. Relationship marketing enjoys a greater impact as communities between sellers and buyers are becoming a fundamental market structure and developing connections is made possible through faster mobile networks and a variety of applications. The evolution of the market structure is characterized by its focus on relationships between different participants rather than isolated transactions.

Matching-choice preference reversal may be another pricing strategy issue to explore (Hsee et al. 2008). Attributes could be weighed differently between product or service providers and consumers. This novel approach could reveal an inconsistency between the pricing strategy employed by providers and a mismatched purchasing pattern among consumers. As more products and services are being designed with the help of IoT technology, information about attributes considered in a consumer's decisionmaking process could be confusing owing to the volume and organization of the information.

Consumers with different levels of knowledge and social experience might have difficulty on evaluating different options when they are facing multi-level promotion schemes. For instance, this might be the case with specific coupons to be used under conditions, with specific categories of products, during a certain period of time, or when the coupon value might change because of timing factors (Hsee et al. 2013). Shopping campaigns like Double $11^{3}$ are becoming a growing trend for many ecommerce platforms, and marketers are using more complex promotion algorithms with precise calculations facilitated by databases and computational techniques. This complexity can cause confusion among consumers, resulting in a higher time cost while choosing between options and decreasing the financial incentive offered through promotion. This phenomenon might reverse marketers' expectation about the effectiveness introduced by data technologies. 
Research on customization is a growing trend in future studies energized by widespread and easily accessed mobile network, data technology, commercialization of practical 3D printing and the development of sharing economy. At the individual level, product and service providers can now provide standardized customization with or without direct feedback from end users, while a potential customization package could be simply calculated from consumer behavioral data and further improved through available feedback from customers. At the business-to-business level, customization has long been a critical component in delivering offerings that correspond with a business customer's special demands. Therefore, researchers might observe new trade-offs on both levels. Customization can be achieved by capturing consumer preferences through gradual pattern recognition and the accumulation of customer behavioral data from multiple sources at different temporal phases before the expected purchase opportunity matures. To achieve a proper balance between customization and universal design, it is important to know in which context either of these product-related strategies and practice is more efficient in relation with firms' developmental priorities such as financial performance or market share acquisition.

\section{Direction 3: International marketing: new opportunities and "going global" strategy research}

The upgradation in economic foundations and social transformation has resulted in Chinese consumers having more influence over the global preferences in the international market. The choices of Chinese customers can compete with those of the customers from developed countries and have first-order impact. This new development raises intriguing inquiries into the ways in which these Chinese preferential categories and mechanisms could impact international production and various sectors such as the movie industry (Hermosilla et al. 2018).

The Belt and Road Initiative provides Chinese firms with fresh opportunities to enter foreign markets in Eurasia. Entering developing countries has posed new challenges which make target country analysis and risk management vital. The innovation-driven marketing strategies that help firms adapt or customize products and services in these markets could be theoretically and practically valuable to explore. Additionally, the competition that Chinese firms might encounter could also become the object of strategy research, especially when it comes to the competition created by local champions and incumbent foreign companies. According to the spillover effect of rivals' entry and expansion in an emerging market (Samaha et al. 2014), learning and mutually enhancing effects could generate new insights into organizational behavior.

\section{Conclusion}

The reform and opening up constantly re-shapes the institutional environment and business climate in China over the 40 years. This constant evolution creates on-going changes and challenges for Chinese consumers and marketers. In this paper, we sample a selection of studies from top-tier marketing journals, thereby outlining a part of the Chinese marketing research landscape from 1978 to 2018. Building upon our analysis

${ }^{3}$ Shuang 11 refers to an online promotion campaign held by the major e-commerce platform, Taobao.com, on 11th November. 
of the existing literature, we find that cultural elements and unique institutional factors are two drivers which offer marketing insights into various domains. We offer several research directions for future academic exploration, taking into account the digitalization of the marketing environment and its dynamic nature. We hope that further efforts will be made in a larger scope of academic works, which will increasingly widen the horizons of market research.

\section{Acknowledgements}

We would like to thank two anonymous reviewers for their constructive inputs and Dr. Fu Yuchuan for her consistent support.

\section{Authors' contributions}

The authors contribute equally to this paper. All authors read and approved the final manuscript.

\section{Funding}

This paper was originally funded by the authors themselves.

\section{Availability of data and materials}

Data sharing is not applicable to this article for this manuscript for its intention in literature review.

\section{Ethics approval and consent to participate}

The Ethics Approval and Consent to Participate are not applicable for this manuscript.

\section{Consent for publication}

Consent for Publication is not applicable for this manuscript.

\section{Competing interests}

The authors declare that they have no competing interests regrading this article.

\section{Author details}

${ }^{1}$ University of International Business and Economics, No.10, Huixin Dongjie, Chaoyang District, Beijing 100029, China. ${ }^{2}$ Capital University of Economics and Business, No. 2 Jintaili, Hongmiao, Chaoyang District, Beijing 100026, China.

Received: 29 November 2018 Accepted: 13 December 2019

Published online: 20 February 2020

\section{References}

Andrews, M., Luo, X. M., Fang, Z., \& Aspara, J. (2014). Cause marketing effectiveness and the moderating role of price discounts. Journal of Marketing, 78(6), 120-142.

Bolton, L. E., Keh, H. T., \& Alba, J. W. (2010). How do price fairness perceptions differ across culture? Journal of Marketing Research, 47(3), 564-576.

Briley, D. A., \& Aaker, J. L. (2006). When does culture matter? Effects of personal knowledge on the correction of culturebased judgments. Journal of Marketing Research, 43(3), 395-408.

Briley, D. A., Rudd, M., \& Aaker, J. (2017). Cultivating optimism: How to frame your future during a health challenge. Journal of Consumer Research, 44(4), 895-915.

Brough, A. R., Wilkie, J. E. B., Ma, J., Isaac, M. S., \& Gal, D. (2016). Is eco-friendly unmanly? The green-feminine stereotype and its effect on sustainable consumption. Journal of Consumer Research, 43(4), 567-582.

Cai, F., Bagchi, R., \& Gauri, D. K. (2016). Boomerang effects of low price discounts: How low price discounts affect purchase propensity. Journal of Consumer Research, 42(5), 804-816.

Calantone, R. J., Schmidt, J. B., \& Song, X. M. (1996). Controllable factors of new product success: A cross-national comparison. Marketing Science, 15(4), 341-358.

Cen, C., \& Quan, J. (2005). The effects of the service attributes to customers' satisfaction: An artificial neural network approach. Nankai Business Review, (2), 16-22.

Chan, K. W., \& Wan, E. W. (2012). How can stressed employees deliver better customer service? The underlying self-regulation depletion mechanism. Journal of Marketing, 76(1), 119-137.

Chan, K. W., Yim, C. K., \& Lam, S. S. K. (2010). Is customer participation in value creation a double-edged sword? Evidence from professional financial services across cultures. Journal of Marketing, 74(3), 48-64.

Chen, J., Fang, J., \& Deng, Z. (2005). Research on integrated measurement model of brand positioning. Nankai Business Review, (2), 23-26.

Chu, J., \& Manchanda, P. (2016). Quantifying cross and direct network effects in online consumer-to-consumer platforms. Marketing Science, 35(6), 870-893.

Cillo, P., Griffith, D. A., \& Rubera, G. (2018). The new product portfolio innovativeness-stock returns relationship: The role of large individual investors' culture. Journal of Marketing, 82(6), 49-70.

Cui, Y. W., Su, Q., \& Li, Z. (2006). An empirical research on relational benefits in e-business environment. Nankai Business Review, (4), 96-103.

Dong, L., \& Tian, K. (2009). The use of western brands in asserting Chinese national identity. Journal of Consumer Research, 36(3), 504-523.

Fan, X., Zheng, Q., Yao, T., \& Mu, L. (2009). What loyalty does customer satisfaction bring? Management World, (2), 83-91. 
Fang, E., Lee, J., Palmatier, R., \& Guo, Z. Y. (2016). Understanding the effects of plural marketing structures on alliance performance. Journal of Marketing Research, 53(4), 628-645.

Fang, E., Palmatier, R. W., Scheer, L. K., \& Li, N. (2008). Trust at different organizational levels. Journal of Marketing, 72(2), 80-98. $\mathrm{Fu}$, L. (2004). The analysis of brand value evaluation of Chinese brands. Management World, (7), 144-145 153.

Gao, H., Zhang, Y., \& Mittal, V. (2017). How does local-global identity affect price sensitivity? Journal of Marketing, 81(3), 62-79.

Gong, S. Y., Zhang, J. J., Zhao, P., \& Jiang, X. P. (2017). Tweeting as a marketing tool: A field experiment in the TV industry. Journal of Marketing Research, 54(6), 833-850.

Graham, J. L., Kim, D. K., Lin, C.-Y., \& Robinson, M. (1988). Buyer-seller negotiations around the Pacific rim: Differences in fundamental exchange processes. Journal of Consumer Research, 15(1), 48-54.

Grewal, R., \& Dharwadkar, R. (2002). The role of the institutional environment in marketing channels. Journal of Marketing, 66(3), 82-97.

Grewal, R., Saini, A., Kumar, A., Dwyer, F. R., \& Dahlstrom, R. (2018). Marketing channel management by multinational corporations in foreign markets. Journal of Marketing, 82(4), 49-69.

Grounoos, C., \& Sun, P. (2001). The internationalization strategy of service companies. Nankai Business Review, (6), 4-7.

Gu, F. F., Hung, K., \& Tse, D. K. (2008). When Does Guanxi Matter? Issues of Capitalization and Its Dark Sides. Journal of Marketing, 72(4), 12-28.

Gu, F. F., Kim, N., Tse, D. K., \& Wang, D. T. (2010). Managing distributors' changing motivations over the course of a joint sales program. Journal of Marketing, 74(5), 32-47.

Guo, R., Tao, L., Wang, T., \& Zhou, N. (2012). Research on strategy after the international merger and acquisition of national brands. Nankai Business Review, (3), 42-50.

Han, J., \& Wei, F. (2001). On the interaction between customer satisfaction and customer loyalty to marketing practice. Nankai Business Review, (6), 8-10.

Han, X., \& Li, Y. (2012). Multi-level model analysis of customer psychological authorization: Adjusting function based on control desire. Nankai Business Review, 3(15), 4-11.

Hermosilla, M., Gutiérrez-Navratil, F., \& Prieto-Rodríguez, J. (2018). Can emerging markets tilt global product design? Impacts of Chinese colorism on Hollywood castings. Marketing Science, 37(3), 356-381.

Hong, R., Wu, S., Yuan, Y., \& Jiang, L. (2017). Research on the impact of social information compliance on customers intention to buy: Based on the social network supporters' WOM. Journal of Marketing Science, (4), 67-82.

Hsee, C. K., Dube, J. P., \& Zhang, Y. (2008). The prominence effect in Shanghai apartment prices. Journal of Marketing Research, 45(2), 133-144.

Hsee, C. K., Zhang, J., Wang, L., \& Zhang, S. (2013). Magnitude, time, and risk differ similarly between joint and single evaluations. Journal of Consumer Research, 40(1), 172-184.

$\mathrm{Hu}$, Y., \& Guo, Y. (2013). Mobile internet customer behavior analysis based on sandglass model. Management World, (7), 184-185.

Hua, G. Y. (1985a). The consumer study 2: Initial exploration of consumer psychology. Management World, (2), 246-257.

Hua, G. Y. (1985b). The consumer study 1: Consuming routines. Management World, (1), 237-249.

Huang, M., Zhou, X., \& Wang, C. (2014). Are more professional customers less loyalty? An empirical study of paradox of customer expertise of fund investors. Nankai Business Review, 17(1), 105-112 144.

Jayachandran, S., Kaufman, P., Kumar, V., \& Hewett, K. (2013). Brand licensing: What drives royalty rates? Journal of Marketing, 77(5), 108-122.

Jerath, K., \& Zhang, Z. J. (2010). Store within a store. Journal of Marketing Research, 47(4), 748-763.

Jia, H., Yang, S., Lu, X., \& Park, C. W. (2018). Do consumers always spend more when coupon face value is larger? The inverted U-shaped effect of coupon face value on consumer spending level. Journal of Marketing, 82(4), 70-85.

Jin, L. (2007). The influence of service warranty on customer expectation and behavioral intention: The mediation effects of perceived risk and value. Management World, (8), 104-115.

Johnson, J., \& Tellis, G. J. (2008). Drivers of success for market entry into China and India. Journal of Marketing, 72(3), 1-13.

Keh, H. T., \& Pang, J. (2010). Customer reactions to service separation. Journal of Marketing, 74(2), 55-70.

Kozlenkova, I. V., Palmatier, R. W., Fang, E., Xiao, B. M., \& Huang, M. X. (2017). Online relationship formation. Journal of Marketing, 81(3), 21-40.

Li, F., \& Liu, Q. (2004). Defining competitive positioning strategy: A comprehensive model. Nankai Business Review, (5),39-43.

Li, F., Ma, B., \& Lin, J. (2010). The effects of emergencies on consumer purchase behavior in retailing. Nankai Business Review, 13(3), 4-11.

Li, F., \& Wang, G. (2006). Research on the improvements of 4Ps marketing mix model. Management World, (9), 147-148 167.

Li, G., Huang, L., \& Lu, H. (2013). OEM special investment, competitive priorities and own brand strategy. Nankai Business Review, 16(6), 28-37.

Li, K. (2001). Thoughts on the improvements of firm value chain. Management World, (5), 207-208.

Li, M., Ma, Q., \& Zhao, X. (2014a). Research on the action mechanism of e-service scape on customer behavioral intention: A perspective on initial trust. Journal of Marketing Science, 10(2), 44-58.

Li, Q., Wei, H., Yang, D., \& Ran, Y. (2016). The effect of imitated kinship between customers and employees on customer repurchase intention: The moderating effects of communication style and customer perceived betrayal. Journal of Marketing Science, 12(1), 89-106.

Li, Z. H., Jin, Y., \& Pu, Q. (2014). Research on the effect of customer participation in value co-creation of virtual brand community on brand equity -The mediating effects of brand experience. Journal of Marketing Science, 10(4), 109-124.

Liang, Y., \& Tan, L. (2005). Value configuration, roles and strategic trade-offs in business ecosystem. Nankai Business Review, (1), $57-63$.

Liu, H. (2000a). The strategies and tactics for overseas enterprises in creating famous brand. Nankai Business Review, (3), 75-77.

Liu, X., \& Jin, Y. (2002). A new model of marketing strategy based on consumers needs and information search. Nankai Business Review, (5), 23-28.

Liu, X., Liu, Y., Yang, Z., \& Wang, H. (2003). The construction of a new customer satisfaction index model based on the analysis of SCSB, ACSI and ECSI. Nankai Business Review, (6), 52-56.

Liu, Z. (2000b). On brand growth strategy. Nankai Business Review, (1), 24-27. 
Lu, J. (2007). A study on the adjusting factors in the relationship between customer satisfaction and customer loyalty--An empirical analysis from Beijing service industry. Management World, (12), 96-105.

Luo, H. C., \& Fan, X. (2005). The relationship marketing mechanism based on psychological contract: An empirical study from service industries. Nankai Business Review, (6), 48-55.

Luo, X., Slotegraaf, R. J., \& Pan, X. (2006). Cross-functional "coopetition": The simultaneous role of cooperation and competition within firms. Journal of Marketing, 70(2), 67-80

Luo, X. M., Andrews, M., Song, Y. P., \& Aspara, J. (2014). Group-buying deal popularity. Journal of Marketing, 78(2), 20-33.

Ma, J., \& Roese, N. J. (2013). The countability effect: Comparative versus experiential reactions to reward distributions. Journal of Consumer Research, 39(6), 1219-1233.

Ma, L. (2011). The research on the impact of CSR on customer intention to buy. Management World, (5), 20-126.

Melnyk, V., Klein, K., \& Volckner, F. (2012). The double-edged sword of foreign brand names for companies from emerging countries. Journal of Marketing, 76(6), 21-37.

Pan, Y., Gao, L., Zhang, X., \& Wan, Y. (2014). Research on the consumer value system in Chinese culture: Scale development and comparison. Management World, (4), 90-106.

Pan, Y., Lu, X., \& Zhu, R. (2005). Building world-class brand: 8R model. Nankai Business Review, (5), 37-40 49.

Petersen, J. A., Kushwaha, T., \& Kumar, V. (2015). Marketing communication strategies and consumer financial decision making: The role of national culture. Journal of Marketing, 79(1), 44-63.

Pu, Q., Jin, Y., \& Li, C. (2017). How does customer favor community and brand: Customer loyalty based on the perspective of value co-creation. Journal of Marketing Science, 13(2), 1-17.

Qin, Y., Cai, L. A., \& Adler, H. (2010). Is it a mixed-based strategy? - A discovery based on a multi-case study. Management World, (10), 135-157 188

Samaha, S. A., Beck, J. T., \& Palmatier, R. W. (2014). The role of culture in international relationship marketing. Journal of Marketing, 78(5), 78-98.

Schmitt, B. H., Pan, Y., \& Tavassoli, N. T. (1994). Language and consumer memory: The impact of linguistic differences between Chinese and English. Journal of Consumer Research, 21(3), 419-431.

Schmitt, B. H., \& Zhang, S. (1998). Language structure and categorization: A study of classifiers in consumer cognition judgment, and choice. Journal of Consumer Research, 25(2), 108-122.

Shen, Q., \& Xiao, P. (2014). McDonald's and KFC in China: Competitors or companions? Marketing Science, 33(2), 287-307.

Sheng, S. B., Zhou, K. Z., \& Li, J. J. (2011). The effects of business and political ties on firm performance: Evidence from China. Journal of Marketing, 75(1), 1-15.

Song, X. M., Xie, J., \& Dyer, B. (2000). Antecedents and consequences of marketing managers' conflict-handling behaviors. Journal of Marketing, 64(1), 50-66.

Steenkamp, J. B. E. M., \& de Jong, M. G. (2010). A global investigation into the constellation of consumer attitudes toward global and local products. Journal of Marketing, 74(6), 18-40.

Su, S., Sun, C., \& Chen, R. (2013). Cultural value, perceived value, and consumer decision-making style in China: A comparison based on urbanization dimension. Nankai Business Review, 16(1), 102-109.

Sun, P. (2016). The decision model of competitive internet products' selection based on internet. Management World, (3), 184-185.

Talukdar, D., Sudhir, K., \& Ainslie, A. (2002). Investigating new product diffusion across products and countries. Marketing Science, 21(1), 97-114.

Tang, X., Jia, J., \& Zhou, T. (2007). A comparison between the value of investment in relationship and the value of promotion by price. Management World, (5), 73-82.

Tavassoli, N. T. (1999). Temporal and associative memory in Chinese and English. Journal of Consumer Research, 26(2), 170-181.

Tellis, G. J., Prabhu, J. C., \& Chandy, R. K. (2009). Radical innovation across nations: The preeminence of corporate culture. Journal of Marketing, 73(1), 3-23.

Tse, D. K., Belk, R. W., \& Zhou, N. (1989). Becoming a consumer society: A longitudinal and cross-cultural content analysis of print ads from Hong Kong, the People's republic of China, and Taiwan. Journal of Consumer Research, 15(4), 457-472.

Van Everdingen, Y., Fok, D., \& Stremersch, S. (2009). Modeling global spillover of new product takeoff. Journal of Marketing Research, 46(5), 637-652.

Varadarajan, P. R., \& Menon, A. (1988). Cause-related marketing: A co-alignment of marketing strategy and corporate philanthropy. Journal of Marketing, 52(3), 58-74.

Vargo, S. L., \& Lusch, R. F. (2004). Evolving to a new dominant logic for marketing. Journal of Marketing, 68(1), 1-17.

Wang, C., Han, X., \& Wen, B. (2003a). An empirical study of the relationship between customer satisfaction and loyalty. Nankai Business Review, (4), 70-74.

Wang, D. T., Gu, F. F., \& Dong, M. C. (2013). Observer effects of punishment in a distribution network. Journal of Marketing Research, 50(5), 627-643.

Wang, J. (2014). An empirical study on the influence of "going out" strategy on China's cultural industry. Management World, $(12), 178-179$

Wang, J. (2016). The classification, innovation and design of business model in business ecosystem. Journal of Marketing Science, 12(01), 1-17.

Wang, L., \& Gao, Y. (2013). Customer relationship model based on Confucianism. Management World, (2), 180-181.

Wang, P., Sun, L., \& Peng, L. (2012). Analyzing the dynamic interaction process of network word-of-mouth: A hierarchical Bayesian selection model based on network reply behavior. Nankai Business Review, 15(5), 141-151.

Wang, P., Wei, J., \& Wang, T. (2010a). Process model and characteristic analysis of financial service innovation. Management World,(4), 168-169.

Wang, W., Keh, H. T., \& Bolton, L. E. (2010b). Lay theories of medicine and a healthy lifestyle. Journal of Consumer Research, 37(1), 80-97.

Wang, X. (2000). The international competitiveness of Chinese home appliance: The formation process and influential factors. Management World, (4), 78-84.

Wang, X. (2005). Research on customer value and its evaluation. Nankai Business Review, (5), 33-36.

Wang, X., Nie, K., \& Chen, R. (2017b). Explain action or explain reaction? Which is more useful? Based upon the effectiveness of online comments in explanation type on consumers' purchasing decision and boundary condition. Nankai Business Review, 20(4), 27-37. 
Wang, Y., Lu, H., \& Wang, D. (2017c). To buy or not to buy: A study on the mechanism of impulsive buying behaviors when group consumers' first reactions are contradictory. Journal of Marketing Science, 13(1), 116-129.

Wang, Y., Wang, K. L., \& Yao, J. T. (2007). An analytical study of marketing model for digital products in the network environment. Nankai Business Review, (6), 26-32.

Wang, Y. D., Feng, X. F., \& Qin, J. (2015). U shape or linear? The effect of service recovery on WOM based on internet. Journal of Marketing Science, 11(4), 91-103.

Wang, Y. G., Chang, J., \& Zhang, D. (2008a). Research on customer asset management and customer asset management capability platform and its composition. Management World, (9), 184-185.

Wang, Y. G., Lee, J., Fang, E., \& Ma, S. (2017a). Project customization and the supplier revenue, cost dilemmas: The critical roles of supplier. Customer coordination. Journal of Marketing, 81(1), 136-153.

Wang, Y. G., Xing, J. G., Shi, Y., \& He, J. (2008). An exploratory study of the relationships among market orientation, customer asset orientation and new product development performance: An empirical analysis of the moderating effect in the context of China. Nankai Business Review, (3), 12-19.

Wang, Y. G., Zhang, Y. L., Yang, Y., \& Li, J. (2003b). The conceptual analysis and empirical study of organizational learning, core competences, strategic flexibility and business competitive performance: Road to dynamic competitive advantage building for China's firms. Nankai Business Review, (4), 54-60.

Wilson, S. (2008). Law : MNCs, state actors, and legal reform in China. Journal of Contemporary China, 17(54), 25-51.

Wu, C. H. (2015). Matching value and market design in online advertising networks: An empirical analysis. Marketing Science, 34(6), 906-921.

Wu, P. P., \& Qiu, G. X. (2007). The empirical study of chain store consuming behavior of Chinese rural customers: Take Heibei as an example. Management World, (11), 168-169.

Wu, X. Y., \& Yuan, L. (2003). On global marketing strategy and integrating global marketing strategy model-implications for Chinese enterprises to develop multinational strategy. Nankai Business Review, (6), 57-62.

Xiao, J., Xie, K., Wu, Y., \& Ran, J. (2014). The capacity building of firm and consumer coordinated evolution: A case study of ecommerce "meng sha". Management World, (8), 134-151.

Xie, Z., \& Zhao, P. (2005). The application of formative model in customer satisfaction measurement model. Nankai Business Review, (2), 4-8.

$\mathrm{Xu}, \mathrm{H}$. (2000). Study on the barriers of EU-China textile trade and the international marketing strategies. Nankai Business Review, (2), 73-76.

Xu, P., Xie, J., \& Chen, R. (2004). Research on firm's implementation decision on customer satisfaction strategy. Management World, (7), 146-148.

Xue, K., \& Yu, M. (2003). Brand extension: Dynamic of brand asset value and theoretical model. Nankai Business Review, (3), 54-60.

Xue, Y. Z., \& Guo, Y. F. (2012). Competitive strategy of e-business sellers on consumer-to-consumer platform: Based on data from taobao.Com. Nankai Business Review, 15(5), 129-140.

Yang, L., \& Wang, Y. (2002). Analysis of customer value and its driving factors. Management World, (6), 146-147.

Yang, Y. H. (1998). Internet marketing and its marketing revolution. Nankai Business Review, (4), 70-73.

Yang, Y. H. (2001). The discussion on firm growth in dynamic environment. Nankai Business Review, (4), 15-19.

Yang, Z. (2000). An integrated model of channel member behavier. Nankai Business Review, (4), 64-70.

Yang, Z. L., Su, C. T., \& Fam, K. S. (2012). Dealing with institutional distances in international marketing channels: Governance strategies that engender legitimacy and efficiency. Journal of Marketing, 76(3), 41-55.

Yao, S., Mela, C. F., Chiang, J. W., \& Chen, Y. X. (2012). Determining consumers' discount rates with field studies. Journal of Marketing Research, 49(6), 822-841.

Yao, S., Wang, W. B., \& Chen, Y. X. (2017). TV channel search and commercial breaks. Journal of Marketing Research, 54(5), 671-686,

Zeithammer, R., \& Kellogg, R. P. (2013). The hesitant Haigui: Return-migration preferences of U.S.-educated Chinese scientists and engineers. Journal of Marketing Research, 50(5), 644-663.

Zhang, H. Y., Zhou, T. Y., Yan, H., \& Tang, X. F. (2014). The influence of online WOM on consumer online behavior. Management World, (3), 178-179.

Zhang, S., \& Schmitt, B. H. (2001). Creating local brands in multilingual international markets. Journal of Marketing Research, 38(3), 313-325.

Zhang, X. G. (2003). Strategies for international competitiveness improvements of Chinese firm in low profits era. Management World, (3), 141-142.

Zhao, X., \& Belk, R. W. (2008). Politicizing consumer culture: Advertising's appropriation of political ideology in China's social transition. Journal of Consumer Research, 35(2), 231-244.

Zheng, M. S. (2000). The connotation and general pattern of the brand strategy. Nankai Business Review, (10), 4-8.

Zheng, X., \& Huang, T. (2010). The analysis of cross region sell supply chain model. Management World, (9), 123-128.

Zhou, K. Z., Yim, C. K., \& Tse, D. K. (2005). The effects of strategic orientations on technology- and market-based breakthrough innovations. Journal of Marketing, 69(2), 42-60

\section{Publisher's Note}

Springer Nature remains neutral with regard to jurisdictional claims in published maps and institutional affiliations. 